\section{US biotech gets a helping hand}

For the fledgling biotechnology industry, the path from start-up to marketplace for a new genetically engineered drug typically has been a long, burdensome and financially uncertain process. But this is about to change in a big way.

The Clinton administration has proposed a series of dramatic reforms to streamline the regulatory process for biotechnology-derived drugs, a move industry and government officials estimate will save millions for companies, reduce paperwork, and speed drug development by months - without compromising public safety.

The changes were immediately embraced by the biotech industry, which has long sought them. In a statement, the Biotechnology Industry Organization, an industry trade group, said they represent "a recognition of the growing importance of the industry in bringing forward the next generation of medicines." The US biotech industry, which is made up of about 1,300 mostly small-to-medium companies, is responsible for all of the two dozen biotech drugs on the US market today and exports about US\$1 billion worth of these products annually.

The proposals, announced in November, are part of the administration's regulatory reform initiatives that were begun last March. "Biotechnology holds great promise for American patients," said Vice President Albert Gore when he announced the changes, along with US Food and Drug Administration (FDA) Commissioner David A. Kessler, and United States Senators Edward M. Kennedy (Democrat, Massachusetts) and Barbara Mikulski (Democrat, Maryland), both of whom represent states with major investments in biotechnology.

The FDA has two centers involved in regulating drugs: the Center for Biologics Evaluation and Research (CBER), which regulates blood, vaccines, and human tissues, and many drugs derived from living organisms, primarily under the Public Health Service Act; and the Center for Drug Evaluation and Research (CDER), which regulates other drugs under the federal Food, Drug and Cosmetic Act.

The drugs made from living organisms regulated by CBER are subject to statutory requirements in addition to those governing all other drugs. For statutory and historical reasons, the two centers have approached biotech regulation differently.
CBER, for example, has required two separate licenses for every biotech drug it regulates, that is, a product license and an establishment license for each facility in which the drug is manufactured. CBER also has required a "lot-by-lot release" for the biotech drugs it regulates, meaning it must oversee the release of each individual lot.

The agency has proposed harmonizing the two centers' policies and requirements for biotech drugs regarded as "wellcharacterized," a description that would apply to most such drugs. The major reforms include:

- Elimination of a licensing procedure that forced a company to seek a separate license for each plant where it planned to produce a drug from "well-characterized" drugs. Under the changes, companies will be required to apply only for one license per drug, regardless of how many manufacturing facilities it expects to construct - the same rule that exists for the regular pharmaceutical industry.

- An end to the requirement that each lot of a drug developed through biotechnology be sent to the FDA for a quality and safety evaluation. Once the agency has okayed a biotech drug, no further licensing will be required. The new rule represents an acknowledgment by the FDA that the industry has manufacturing standards on a par with all those in the pharmaceutical industry.

- A commitment by the FDA to review and respond within 30 days of a company submitting additional information requested by the agency after it has put a clinical trial on hold. If the agency fails to respond, the trial may proceed without penalty to the company. In the past, the FDA had no deadline in this regard.

- Elimination of the need for approval of promotional labeling before launching a new product, a change that will also help free FDA's resources for other matters.

- Revision of the manufacturers' requirements to appoint a "responsible head" for compliance and official contacts with the FDA, allowing firms to divide management responsibility among the appropriate regulatory, medical or manufacturing staff. These individuals will be able to communicate directly with the agency on official matters related to their company's biotech products.

MaRlene Cimons Washington, $D C$

\section{DID YOU KNOW?}

\section{Baboon bone marrow transplanted to AIDS patient}

On 14 December, four months after the Food and Drug Administration approved the risky procedure, AIDS patient Jeff Getty of Oakland, California, received an experimental transplant of baboon bone marrow in an attempt to boost his failing immune system. This is the first time this type of xenotransplantation has been done in a human being. Getty's doctors hope that the baboon bone marrrow cells, which are resistant to HIV infection, will help the patient's own bone marrow to develop virus-resistant T cells.

According to Steven Deeks of the University of California at San Francisco, one of Getty's attending physicians, it will take "three to six months to determine whether or not we see the development of baboon-derived cells."

The procedure has been opposed by animal right groups and by scientists who fear the introduction of new diseases into humans from the baboon transplant.

FinTAN R. STEELE

\section{News from the Net}

OMNI (Organising Medical Network Information) is a new Internet service launched in late November in the UK that provides scientists, students and practitioners with access to a broad array of information in the areas of clinical medicine, biological sciences, health professions, public health and health management. The service is being provided by a seven-member consortium, led by the National Institute for Medical Research and including the British Medical Association. Interested parties can access OMNI on the World Wide Web at URL http://omni.ac.uk. JENNIFER K. SNOW

\section{The cutting edge of medicine}

It was bound to happen. The first reported case of a patient swallowing an unwrapped blister-packaged pill and puncturing his intestine appears in the 11 November 1995 issue of the Lancet. Even though blister-packaging of pills was designed to protect consumers against pill tampering, the sharp edge of the package can apparently be a hazard itself. The patient, a 68-year-old Norwegian who was recovering from heart surgery at National Hospital in Oslo, is doing well after removal of part of his intestine. Doctors warn that people with vision difficulties or who are confused should never be given pills unless the packaging is removed first.

FinTAN R. STEELE 